\title{
The impact of particle shape on the angle of internal friction and the implications for sediment dynamics at a steep, mixed sand-gravel beach
}

\author{
N. Stark ${ }^{1, *}$, A. E. Hay ${ }^{1}$, R. Cheel ${ }^{1}$, and C. B. Lake ${ }^{2}$ \\ ${ }^{1}$ Dalhousie University, Department of Oceanography, Halifax, Canada \\ ${ }^{2}$ Dalhousie University, Department of Civil Engineering, Halifax, Canada \\ *now at: Virginia Tech, Department of Civil and Environmental Engineering, Blacksburg, VA, USA \\ Correspondence to: N. Stark (ninas@ vt.edu)
}

Received: 14 October 2013 - Published in Earth Surf. Dynam. Discuss.: 10 December 2013

Revised: 18 July 2014 - Accepted: 24 July 2014 - Published: 27 August 2014

\begin{abstract}
The impact of particle shape on the angle of internal friction, and the resulting impact on beach sediment dynamics, is still poorly understood. In areas characterized by sediments of specific shape, particularly non-rounded particles, this can lead to large departures from the expected sediment dynamics. The steep slope $(1: 10)$ of the mixed sand-gravel beach at Advocate Harbour is stable in large-scale morphology over decades, despite a high tidal range of $10 \mathrm{~m}$ or more, and intense shore-break action during storms. The Advocate sand $(d<2 \mathrm{~mm}$ ) was found to have an elliptic, plate-like shape (Corey Shape Index, CSI $\approx 0.2-0.6$ ). High angles of internal friction of this material were determined using direct shear, ranging from $\phi \approx 41$ to $49^{\circ}$, while the round to angular gravel was characterized as $\phi=33^{\circ}$. The addition of $25 \%$ of the elliptic plate-like sand-sized material to the gravel led to an immediate increase in friction angle to $\phi=38^{\circ}$. Furthermore, re-organization of the particles occurred during shearing, characterized by a short phase of settling and compaction, followed by a pronounced strong dilatory behavior and an accompanying strong increase of resistance to shear and, thus, shear stress. Long-term shearing $(24 \mathrm{~h})$ using a ring shear apparatus led to destruction of the particles without re-compaction. Finally, submerged particle mobilization was simulated using a tilted tray submerged in a waterfilled tank. Despite a smooth tray surface, particle motion was not initiated until reaching tray tilt angles of $31^{\circ}$ and more, being $\geq 7^{\circ}$ steeper than for motion initiation of the gravel mixtures. In conclusion, geotechnical laboratory experiments quantified the important impact of the elliptic, plate-like shape of Advocate Beach sand on the angles of internal friction of both pure sand and sand-gravel mixtures. The resulting effect on initiation of particle motion was confirmed in tilting tray experiments. This makes it a vivid example of how particle shape can contribute to the stabilization of the beach face.
\end{abstract}

\section{Introduction}

Subaqueous sediment dynamics play a major role in coastline, river and lake development, as well as scour around submerged structures, and coastal hazards such as submarine landslides (Kuehl et al., 1996; Simons and Şentürk, 1992; Bradley and Stolt, 2006; Masson et al., 2006). Despite the widespread interest and ongoing research in this field, the complex system consisting of the many diverse factors governing subaqueous sediment dynamics and beach dynamics (hydrodynamics, morphology and sediment properties) is still far from being fully understood. Focusing on the sediment properties, the friction angle is known to be a major factor controlling the critical shear stress required to initiate particle motion (Middleton and Southard, 1984; Bagnold, 1988; Kirchner et al., 1990; Soulsby, 1997). The friction angle depends on grain size, sorting, density, particle arrangement, and particle shape (Schanz and Vermeer, 1996; Das, 1990). In particular, the importance of particle shape with regard to the friction angle and initiation of subaqueous 


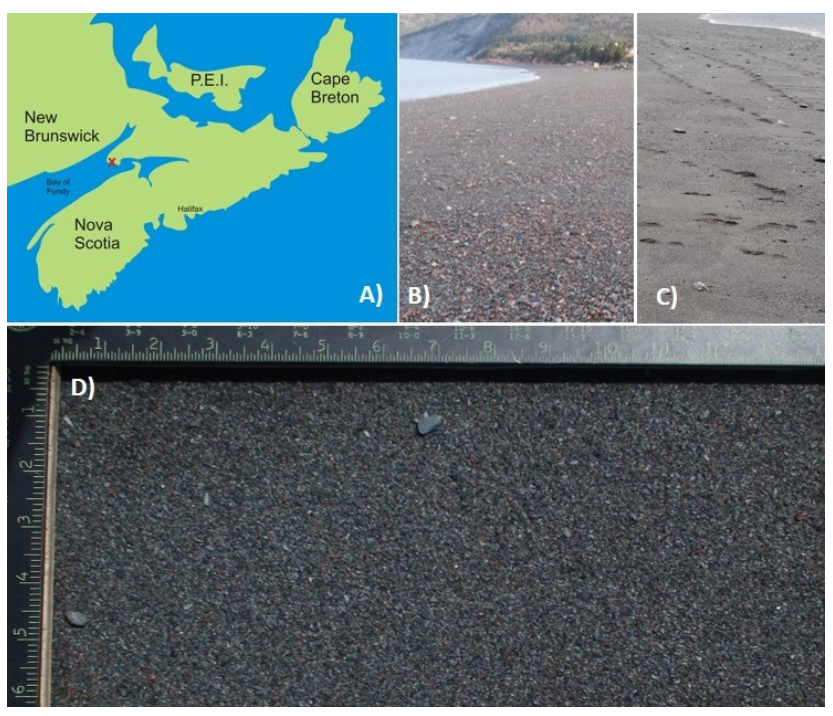

Figure 1. (a) The location of Advocate Harbour at the Bay of Fundy between Nova Scotia and New Brunswick, Canada. (b) Photograph of the beach face at low water during calm weather conditions. (c) Photograph of the beach face at low water after a storm event. (d) Photograph of the surficial sediments after a storm event (scale in inches).

sediment motion was pointed out by Kirchner et al. (1990) for river sediments. Generally, there is still a certain lack of data pertaining to the impact of particle shape - particularly non-rounded shapes - on subaqueous sediment dynamics and beach morphodynamics.

The mixed sand-gravel beach near Advocate Harbour (Fig. 1) was investigated in the framework of a sediment dynamics experiment in May 2012. Hydrodynamics, largeand small-scale morphology, and sediment distribution were monitored over 3 weeks. With regard to the latter, a distinct cross-shore zonation varying with the lunar tidal cycle and weather/hydrodynamic conditions was observed (Stark et al., 2014b). However, despite the energetic hydrodynamics at the beach during wind-wave forcing events in particular, the beach slope has remained constant at about $6.4^{\circ}$ for decades. Also - and rather surprisingly - following a significant storm wave event, the beach face was dominated by sandy sediments (Fig. 1). As documented in a companion paper (Hay et al., 2014), the fine-grained surficial sediments observed during active wave-forced conditions were associated with a very particular size-sorting process involving the development of orbital-scale (or vortex) ripples on the beach face during the rising tide. The sandy sediments $(d<2 \mathrm{~mm})$ were characterized by a strong variations in particle shape, and a high abundance of flat, elliptic particles (Fig. 2). As a result, it was hypothesized that the flat, elliptic shape of the sand-sized particles impacts the friction angle and, by doing so, contributes to the stability of the beach.
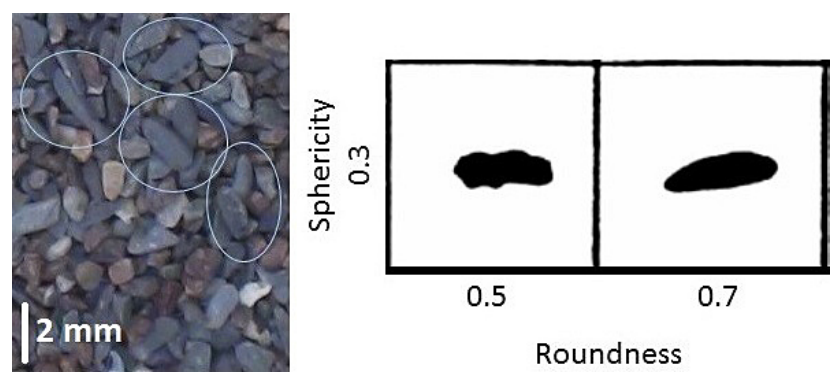

Figure 2. Left panel: example of flat, elliptic sand particles. Right panel: particle shapes which reached the highest friction angles in the study of Cho et al. (2006) (modified after Santamarina and Cho, 2004).

This hypothesis is in agreement with findings by, e.g., Miller and Byrne (1966). Instead of the geometric approach to estimate the average friction angle by Eagleson and Dean (1961), they proposed the following equation:

$\bar{\phi}=\alpha_{\mathrm{mb}}(d / \bar{K})^{-\beta}$,

where $\bar{\phi}$ is the average friction angle, $d$ is the test grain diameter (tests were conducted with one single loose particle on a fixed rough bed), $\bar{K}$ is the average diameter of the bed grains, and $\alpha_{\mathrm{mb}}$ and $\beta$ are parameters fitted by regression to the data. Regarding the latter, Miller and Byrne (1966) found that $\alpha_{\mathrm{mb}}$ was sensitive to the particle shape, and increased with decreasing sphericity. Li and Komar (1986) specified that $\alpha$ increased with particle flatness (i.e., with the decrease of the ratio of the smallest and intermediate axial diameters $S / I$ ). Additionally, these authors found that $\beta$ was influenced by particle shape when comparing spheres to smooth ellipsoidal pebbles. However, Kirchner et al. (1990) argued that there is no consistent relationship between $\alpha_{\mathrm{mb}}$ and grain shape in the literature, and that more controlled experiments are required. Nevertheless, these authors also found a decrease of median friction angle by $10-15^{\circ}$ by eliminating grain roughness, meaning approaching spherical particles. Buffington et al. (1992) stressed the importance of testing friction angles of the native sediments to estimate critical shear stresses instead of relying on the grain size and neglecting particle shape. They presented results from testing naturally formed gravel from a streambed with Corey Shape Indices CSI $=0.57-068$, indicating compact but not yet rounded particles (Illenberger, 1991). The results supported the discussion by Kirchner et al. (1990) that the empirical relationship obtained by Miller and Byrne (1966) cannot be generally applied using coefficients $\alpha$ and $\beta$ determined from other samples.

Riley and Mann (1972) focused particularly on flat particles (i.e., "flakes"). They found that the angle of repose increased in the order of spheres, cylinders, angular particles and flakes for glass particles in the same size. Flakes with a particle size of $16 \mathrm{~mm}$ reached angles of repose of $\sim 38.27^{\circ}$, but the authors argued that they expected even higher angles 
Table 1. Summary of sediment properties and shear test result terms of median grain size $d_{50}$, modality (unimodal vs. bimodal), maximum shear stress measured for the highest load level of the respective sample in the direct shear boxes $\tau_{\max }$, internal angle of friction $\phi_{\text {max }}$, maximum observed vertical displacement during shearing in the respective direct shear box (dilation is positive) and tray tilt angle when sediment started moving $\alpha_{\text {tray }}$.

\begin{tabular}{lllrrrr}
\hline Sample & $d_{50}(\mathrm{~mm})$ & Modality & $\begin{array}{r}\tau_{\max } \\
(\mathrm{kPa})\end{array}$ & $\begin{array}{r}\phi \\
\left({ }^{\circ}\right)\end{array}$ & $\begin{array}{r}\text { Dilation } \\
(\mathrm{mm})\end{array}$ & $\begin{array}{r}\alpha_{\text {tray }} \\
\left({ }^{\circ}\right)\end{array}$ \\
\hline Sand: reef & 0.28 & unimodal & 28 & 41 & 0.2 & \\
Sand: fine sand patch & 0.27 & unimodal & 30 & 42 & 0.4 & \\
Sand: Pos 182 (yd 131) & 0.78 & unimodal & 32 & 42 & 0.2 & \\
Sand: Pos 184 (yd 131) & 0.92 & unimodal & 38 & 49 & 0.6 & \\
Sand: Pos 186 (yd 125) & 1.0 & unimodal & 35 & 44 & 0.1 & 31 \\
Sand: Pos 186 (yd 131) & 1.1 & unimodal & 36 & 49 & 0.5 & \\
Sand: Pos 187 (yd 125) & 1.2 & unimodal & 35 & 46 & 0.6 & \\
\hline Gravel: Pos 181 (yd 125) & 12.5 & unimodal & 89 & 32 & -1.4 & 24 \\
75\% gravel and 25\% sand: & 12.5 and 1.0 & bimodal & 113 & 38 & -4.7 & \\
50\% gravel and 50\% sand: & 12.5 and 1.0 & bimodal & 113 & 38 & -4.6 & \\
\hline
\end{tabular}

of repose, and that such values were probably not reached because the flakes always packed with their flat faces horizontally, making slipping easier. This conclusion highlights the need for investigations of shearing behavior dependence on particle shape to fully understand sediment transport.

The detailed investigation of shearing behavior is traditionally a research focus in geotechnical engineering and soil mechanics, and the impact of particle shape on shearing behavior and angle of internal friction has been recognized for some time (Terzaghi, 1943; Taylor, 1948; Craig, 1974; Das, 1990). More recently, Santamarina and Cho (2004) and Cho et al. (2006) discussed the role of particle shape in soil behavior. Among other results, they showed that a decrease in particle regularity that included sphericity and/or roundness leads to an increase in the constant volume critical state friction angle, with the constant volume critical state referring to a state of static equilibrium between volume reduction as a consequence of chain collapse and volume dilation during shearing (Santamarina and Cho, 2004). In the Cho et al. (2006) experiments, constant volume critical state friction angles of up to $41^{\circ}$ were documented for a crushed sand with a median grain size of $0.48 \mathrm{~mm}$, a high angularity and a medium sphericity (Fig. 2).

In this study, standard geotechnical laboratory shear tests (direct uniaxial shear and ring shear test apparatuses) were applied (i) to test the applicability of standard geotechnical shearing experiments for the investigation of shearing processes of beach sediments, and (ii) to test the hypothesis of whether the flat, elongated particle shape of the sand-size fractions of the Advocate Beach sediments potentially contributes to the stabilization of the beach face. The study was initially motivated by the high abundance of surprisingly fine particles on the beach face after energetic storm wave events. The geotechnical results were complemented by a simple physical simulation of sediment mobilization along a tilted tray that contributed to the understanding of particle transport of the Advocate Beach sediments. More technical details and results from the latter laboratory study are presented in Stark et al. (2014a).

\section{Methods}

Beach samples (Table 1) were collected along a cross-shore transect in the vicinity of an instrumented frame that was installed for the full 3 weeks of the experiment. The frame was equipped with a number of different acoustic and other devices estimating flow velocity, bed-load transport velocity, wave orbital velocity, wave height and small-scale morphological variations (Hay et al., 2014). Sampling locations along this cross-shore transect reached from the berm down to the low water level, $10 \mathrm{~m}$ apart from one another (position 181 (berm) through position 188 (low water level)). Additionally, samples from two fully submerged sites in about $1.5 \mathrm{~m}$ water depth at low water were collected at sand patches, and close to a reef-like assembly of boulders and rocks. These samples represent surficial sediment samples, and were taken using a small shovel.

\subsection{Geotechnical laboratory experiments}

Three different shear devices were used: a small direct shear box $(100 \mathrm{~mm} \times 100 \mathrm{~mm})$ for sandy sediments only, a large direct shear box $(300 \mathrm{~mm} \times 300 \mathrm{~mm})$ for gravel and sandgravel mixtures, and a ring shear device for $24 \mathrm{~h}$ tests of the sand samples. The direct shear test is the oldest and simplest shear test arrangement in geotechnical engineering (Das, 1990). The specimen is placed in a metal box that is split horizontally in halves. In the case of fully or partially saturated samples, porous plates are placed on top and below of the specimen to allow free drainage and avoid pore pressure buildup. A normal force is applied via a loading plate on 
the specimen. The minimum normal load equals the weight of the loading plate and the porous plate, while loads can be as great as $\sim 1000 \mathrm{kPa}$ (Das, 1990). Vertical displacement of the specimen is measured by recording the vertical motion of the loading plate using a mechanical displacement sensor. The shear tests could theoretically be performed without load, loading plate and top porous plate, but then measurements of vertical displacement would be difficult. After establishing the desired normal force, the lower half of the box is displaced horizontally at a chosen shear rate. The specimen experiences shear stress along the shear plane between the two halves of the box measured using a load cell. The results are commonly expressed as horizontal displacement versus vertical displacement, expressing dilation or contraction of the specimen during the shearing process, and as horizontal displacement versus shear stress. Different profiles are expected depending on the packing of the specimen. For example in the case of loose sand, the resisting shear stress increases with horizontal displacement until an approximately constant value $\tau_{\mathrm{f}}$ (failure shear stress) is reached, while compaction dominates the vertical displacement (Terzaghi, 1943; Poulos, 1971; Das, 1990). In the case of densely packed sand, the shear stress increases to a maximum, the peak shear stress $\tau_{\mathrm{f}}$, while the specimen undergoes a compaction followed by dilation until reaching $\tau_{\mathrm{f}}$. Subsequently, the shear stress gradually decreases until reaching the critical state shear stress $\tau_{\mathrm{cv}}$ (Terzaghi, 1943; Poulos, 1971; Das, 1990). No significant vertical displacement is observed in this phase.

Specimens of the same samples are then tested at various normal stresses, and plotting the normal stresses versus the corresponding shear stress allows an estimate of the angle of internal friction by application of the Mohr-Coulomb failure criterion (Terzaghi, 1943; Poulos, 1971; Das, 1990):

$\tau_{\mathrm{f}}=c+\sigma \tan \phi$,

with $c$ the cohesion, $\sigma$ the normal stress and $\phi$ the angle of internal friction. With this approximation, $\phi$ determined from tests with a range of normal stresses, including relatively high normal stresses, would still be applicable for the low range of normal stresses. Thus, the shear test results can be applied to beach surface sediments which are exposed to a minimal normal stress.

Different denotations can be found regarding $\phi$. Terzaghi (1996) referred to the effective-stress friction angle, the angle of internal friction or the angle of shearing resistance $\phi$ ' when plotting the normal stress versus the peak shear stress $\tau_{\mathrm{f}}$. Taylor (1948) and Rowe (1962) denoted this as $\phi_{\max }$. Plotting the normal stress versus the critical state shear stress allows one to extract the critical state or constant-volume friction angle $\phi_{\mathrm{cv}}$ (Taylor, 1948; Rowe, 1962; Terzaghi, 1996). In the case of loose sand, it can be assumed that $\phi_{\max } \approx \phi_{\mathrm{cv}}$. For dense sands $\phi_{\max }>\phi_{\mathrm{cv}}$ applies as a result of the impact of dilation on shear strength (Taylor, 1948; Rowe, 1962; Terzaghi, 1996). Regarding application to the beach environment, dilation or compaction of the beach surface sediment under initiation of motion and shearing is expected due to particle rearrangement. Thus, the determination of the peak shear stress and the angle of internal friction is desired here. In the following, we will denote the angle of internal friction by $\phi$.

\subsubsection{Direct shear box}

For the direct shear tests of the sand-sized fractions, a standard-sized small shear box (surface area $=36 \mathrm{~cm}^{2}$ ) was used, and the sediment was filled in loosely and watersaturated. Each sample was tested at three different normal stresses: 3, 32, and $64 \mathrm{kPa}$. This is significantly lower than normal stresses usually applied for subsoil testing to account for low normal stresses at the beach-face sediment surface. Between the tests, the samples were stirred to ensure a loose particle arrangement at the start of shearing.

The larger direct shear apparatus was used for shearing the gravel and gravel-sand mixtures. Mixtures of $100 \%$ gravel, $75 \%$ gravel mixed with $25 \%$ sand, and $50 \%$ gravel mixed with $50 \%$ sand were tested at normal stresses of 51, 99, and $149 \mathrm{kPa}$, which were the lowest normal stresses feasible with the large direct shear apparatus. Similar to the small direct shear box, samples were loosely installed, and stirred after each test.

The direct shear tests were used to monitor the development of shear stress with horizontal shearing of the sample to determine the angle of internal friction. Furthermore, any compression or expansion of the samples during shearing was recorded.

\subsubsection{Ring shear test}

Shearing behavior over $24 \mathrm{~h}$ was tested using a ring shear apparatus (also called annular direct shear apparatus). Here, an annular specimen (sand or finer sediments only) is sheared, under a given normal stress $(92 \mathrm{kPa}$, the lowest normal stress the apparatus allowed; $461 ; 922 \mathrm{kPa}$ ), on a horizontal plane by the rotation of the annular sample relative to a stationary lid (Craig, 1974). This test was mainly conducted to observe long-term dilatory behavior.

\subsection{Physical simulation of sediment remobilization}

A smooth tray with a hopper feeding sediment onto the tray was arranged in a tank filled with water, and was tilted to angles ranging between 20 and $40^{\circ}$ (Stark et al., 2014a). The angle at which sediment started moving $\alpha_{\text {tray }}$, and average particle velocities $u$ were determined via video observations, and via a prototype wide-band coherent Doppler profiler (MFDop) (Hay et al., 2008, 2012a, b). In this study, the main interest was to determine how easily the gravel and sand can be mobilized in comparison to each other, and other gravel types. 

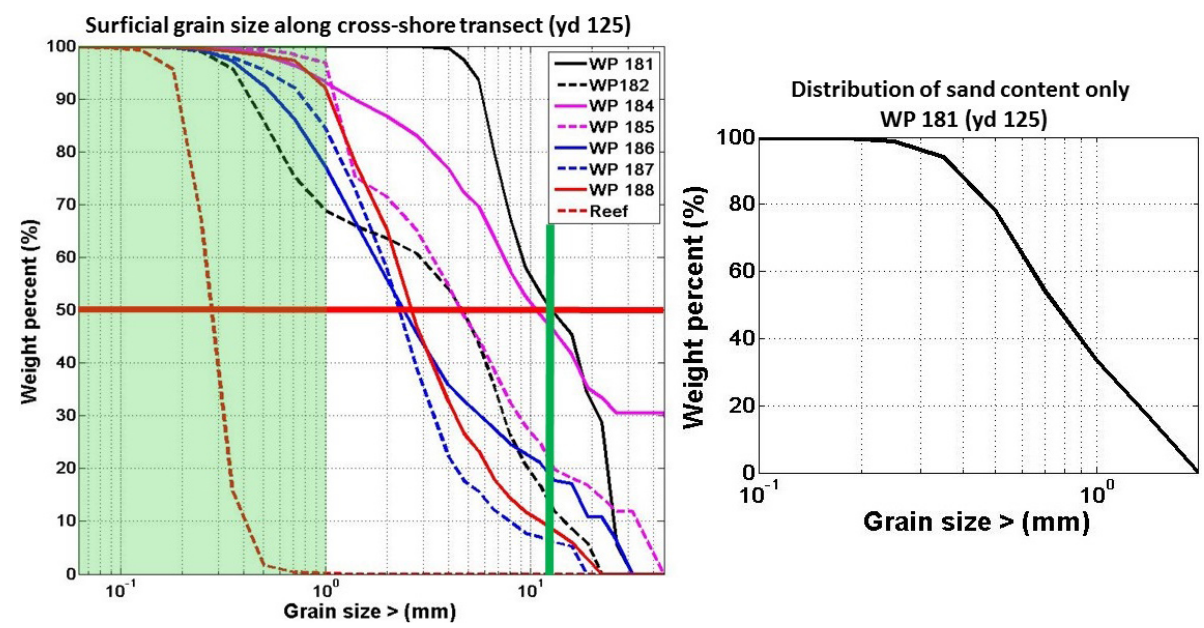

Figure 3. Left panel: representative grain size distributions for beach surface samples collected along a cross-shore profile with position WP 188 being the low tide level and WP 181 at the berm on year day 125. The green bars indicate the grain size range which has been tested in the laboratory shear tests. The red bar indicates the $50 \%$ mark at which median grain size $d_{50}$ is determined. Right panel: representative distribution of grain size of sand fraction only $(<2 \mathrm{~mm})$ extracted from the sample taken at position WP 181 on year day 125 . This sample has been tested in the direct shear box.

\section{Results}

\subsection{Sediment description}

The sampled sediment showed a strong variation in grain size distributions $\left(d_{50}=0.3-18.5 \mathrm{~mm}\right)$ along the cross-shore transect, as well as depending on the hydrodynamic conditions (Table 1 and Fig. 3). The finest sediments were found at the fully submerged sites $\left(d_{50}=0.3 \mathrm{~mm}\right)$, while the most finegrained samples from the beach face were characterized by $d_{50} \approx 1 \mathrm{~mm}$. Figure 3 shows representative grain size distributions along a cross-shore transect, and a detailed grain size distribution of a representative sand sample used for the laboratory testing.

Within the sand-sized fractions $(d<2 \mathrm{~mm})$, strong variations in particle shape with a high abundance of flat, elliptic particles were observed (Fig. 2). Grains of a sediment sample from a representative location at the beach surface (Pos. 184) were measured with regard to longest axis length $(L)$, intermediate axis length $(I)$ and shortest axis length $(S)$ to determine disc-rod index $(\mathrm{DRI}=(L-I) /(L-S))$ and Corey Shape Index $(\mathrm{CSI}=S /(\sqrt{I L}))$ after Illenberger (1991). Most of the particles were rather elongated and ranged from extremely flat to compact (Fig. 4). Compact particles were predominantly of gravel size. Low DRIs in the case of the sand particles can likely be associated with broken particles.

The samples were dominated by sandstone, in accordance with geological studies of the region by, e.g., Amos and Long (1980), Amos et al. (1991) and Dalrymple et al. (1990). Particle densities of randomly chosen samples were consistently $2.4-2.5 \mathrm{~g} \mathrm{~cm}^{-3}$.

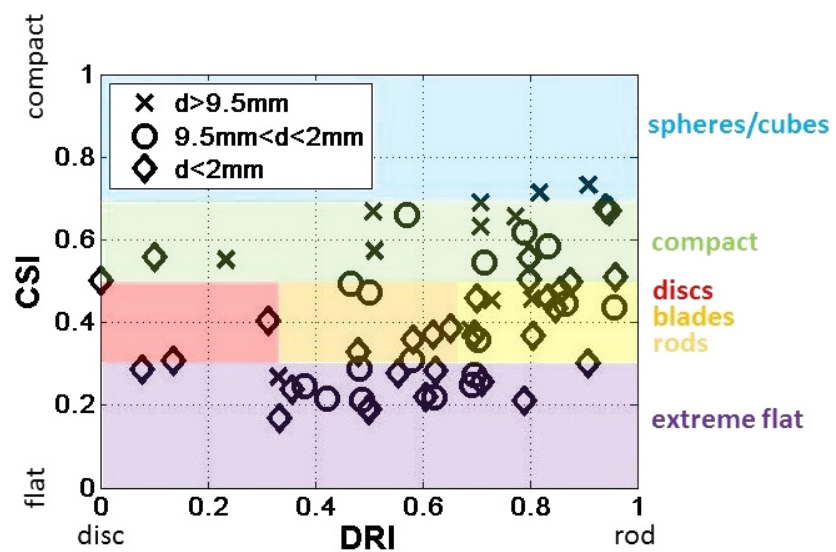

Figure 4. Sample measurements of particle shape expressed as disc-rod index (DRI) and Corey Shape Index (CSI). Description and schematic modified after Illenberger (1991).

\subsection{Geotechnical laboratory experiments}

\subsubsection{Direct shear box}

The plots of horizontal displacement versus shear stress (Fig. 5) illustrate the different response to applied shear stress for the different loading stages. At the lowest applied normal stress, sample failure occurred at a low value of the applied shear stress. At the second loading stage, we found some stress-vs.-horizontal displacement curves which matched a shear stress path expected in the case of loose sediments, and some which already showed a tendency towards a peak shear strength, as expected for denser sand. In some cases, a step-like feature was observed in the stress-vs.-horizontal displacement curves, likely corresponding to processes of 


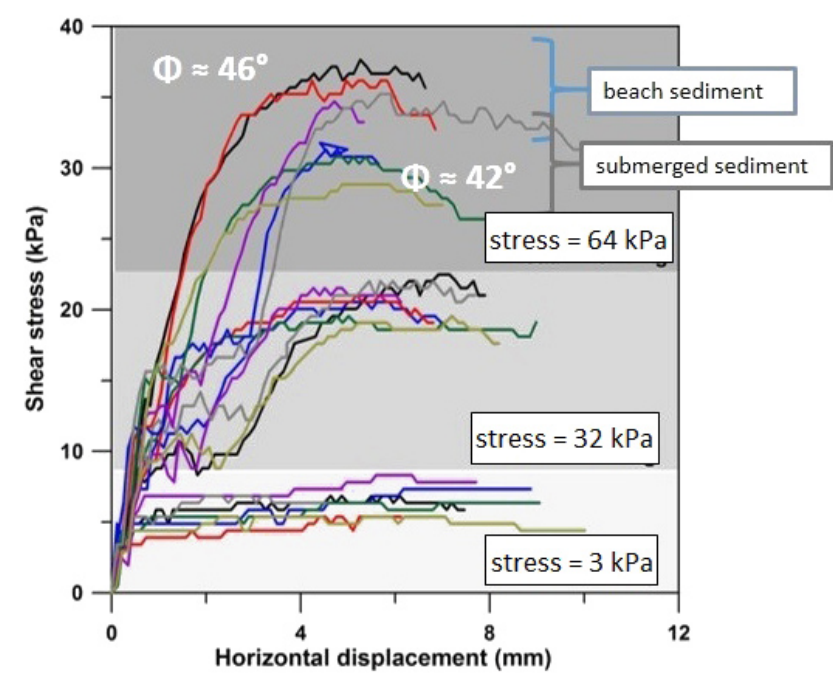

Figure 5. Horizontal displacement versus shear stress of samples with a grain size $d \leq 2 \mathrm{~mm}$ measured in the small direct shear box. The different stages of normal stress are indicated by different gray shades. At the highest loading stage, a difference in the shear stress path between the beach-face sediments and samples from permanently submerged sites can be observed, leading to differences in the internal angle of friction $\phi$.

re-arrangement of the particles. The same was true for the highest normal load. Here, we additionally observed clear differences between the samples from the beach face and those from the permanently submerged sites. Analysis of the profiles led to $\phi \approx 46^{\circ}$ for the beach-face sands and $\phi \approx 42^{\circ}$ for the sand from the permanently submerged sites.

The vertical displacement was characterized by a twophase behavior that was approximately similar for all sands independent of their origin (Fig. 6). First, a phase of specimen compaction, i.e., a negative vertical displacement, was observed, corresponding to the range of horizontal displacement when also the first plateau in the step-like shear stress profiles was noted. This observation supports the hypothesis of particle re-arrangement and alignment during this phase. After this compaction phase, a strong dilation behavior is characteristic of the Advocate Beach samples, reaching significantly larger positive vertical displacements than the previous negative vertical displacement (Fig. 6).

The gravel tests in the large direct shear box revealed typical shear stress profiles, as expected for loose granular material (Fig. 7), and led to $\phi \approx 33^{\circ}$ for the pure gravel sample, while the addition of sand resulted in an increase to $\phi \approx 38^{\circ}$. The vertical displacement was characterized by compaction: no dilation was observed.

\subsubsection{Ring shear test}

The vertical displacement during shearing was investigated in more detail in the $24 \mathrm{~h}$ ring shear tests (Fig. 8). Under all three values of normal stress, the specimen expressed the

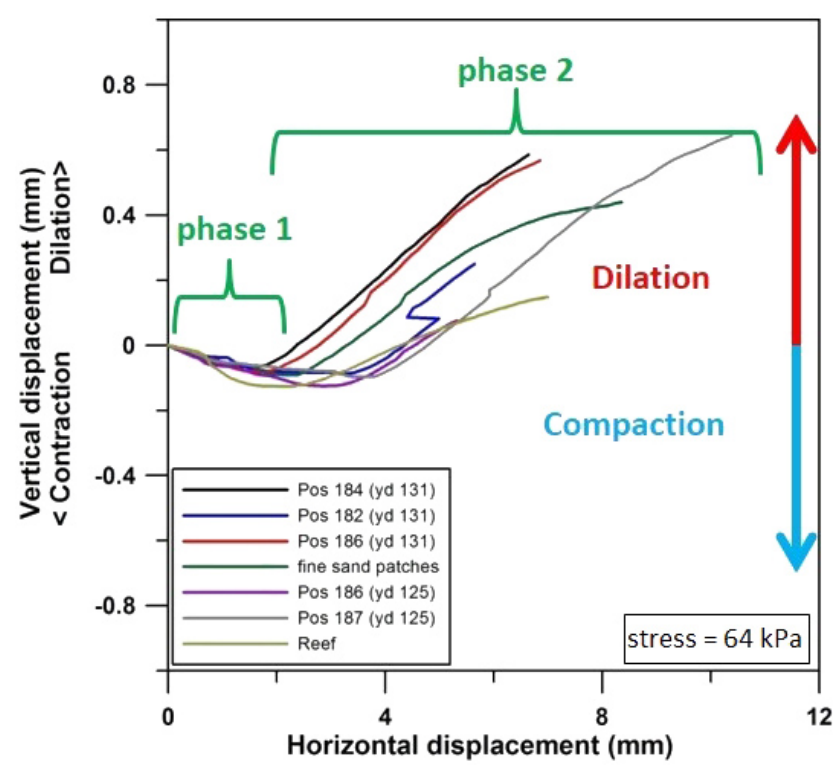

Figure 6. Horizontal displacement versus vertical displacement of samples with a grain size $d \leq 2 \mathrm{~mm}$ measured in the small direct shear box under the highest normal stress. First a short phase of compaction was observed, before a strong dilation was monitored.

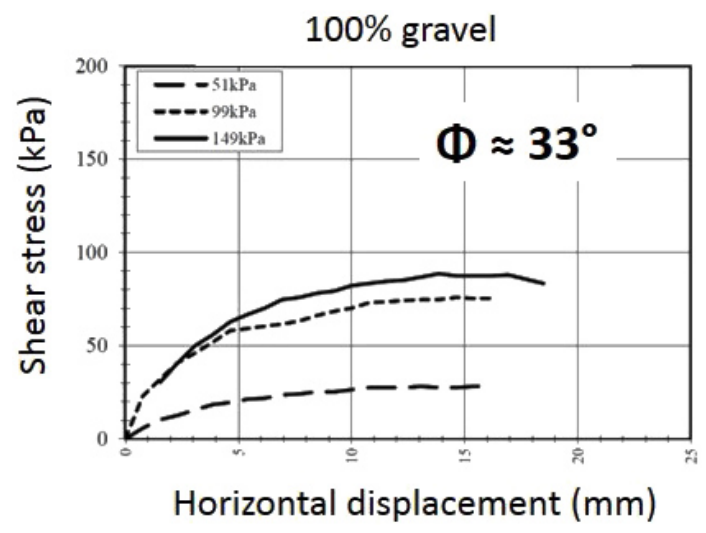

Figure 7. Horizontal displacement versus vertical displacement of gravel measured in the large direct shear box.

previously described phases of compaction and stronger dilation. However, under the much higher normal stresses tested in the ring shear, it stood out that the magnitude of compaction as well as dilation is governed by the normal stress. Nevertheless, a noticeable compaction followed by a strong dilation was confirmed by the low normal stress measurements in the ring shear apparatus, likely the test closest to the in situ beach-face conditions where normal stresses are low. Afterwards, a stagnation is reached in which the vertical displacement level remains constant, before it comes to another negative vertical displacement, governed in magnitude by the normal stress stage again. Furthermore, it was observed that over the long-term shearing the sand experienced a process 


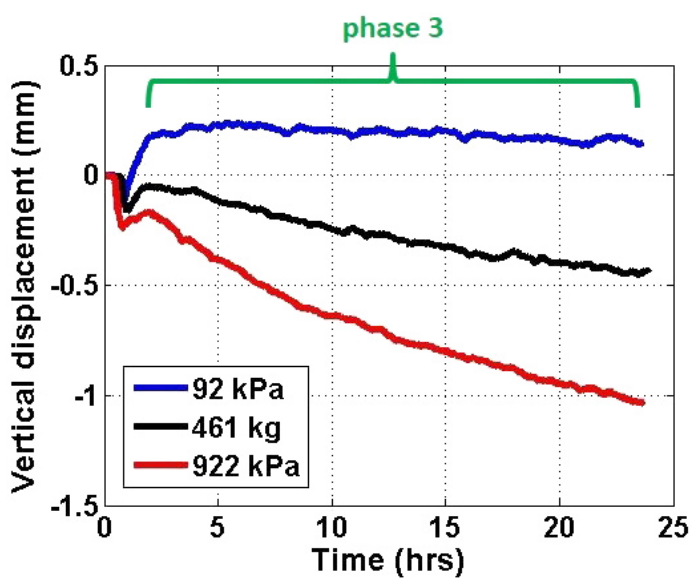

Figure 8. Vertical displacement versus time for a sand sample measured in the ring shear apparatus. After the previously described phases 1 and 2 of vertical displacement, the specimen shows a third phase of behavior: a return to negative vertical displacement. The magnitude is governed by the normal stress. Also, the intensity of dilation in phase 2 seemed to be restricted by the normal stress.

such as grinding. The particle sizes at the shear face were reduced and, in the case of the highest normal stress, down to a silt size level.

\subsection{Physical simulation of sediment remobilization}

In a simple physical simulation, we tested the initiation of particle motion of sand and gravel from Advocate in comparison to each other, and to other commercially available gravel. The test series was part of a larger effort investigating the suitability of a new wideband coherent acoustic Doppler profiler for the investigation of coarse sediment transport. Detailed results and discussion can be found in Stark et al. (2014a). The tray tilt angle $\alpha_{\text {tray }}$ at which first particle motion was correlated to the respective transport velocities reached approximately the center of the tray and was measured using the acoustic Doppler profiler MFDop and video observations. The Advocate gravel showed a behavior similar to more angular, as well as more rounded commercially available gravel. Deviations depending on shape and size were observed, but will not be discussed in detail in this article. A more distinctively different behavior was observed in the case of the sand. Initiation of particle motion of the Advocate sand did not start until tray tilt angles of $31^{\circ}$ were reached, while all gravel size particles started moving at tray tilt angles of $21-24^{\circ}$. This trend matched the observation of the angle of internal friction determined by direct shearing; however, the exact values did not match. The difference can be explained with the experimental setup. The majority of the sediment was fed from a hopper which was mounted to the tray. Nevertheless, it has to be considered that the predominant "failure" or slipping plane was the tray-sediment interface, likely leading to the initiation of particle motion at lower inclinations.

\section{Discussion}

The application of geotechnical laboratory experiments to investigate the behavior of elliptically shaped beach sediment under shear stress proved to be a suitable and useful approach to study the response to applied shear under controlled conditions. Nevertheless, some issues have to be considered. First, the collected samples hardly represented the in situ texture at the beach face, in particular in a submerged state, and under active flow and wave action. This is a well-recognized issue regarding sediment sampling in the field of subaqueous sediment dynamics (Blomqvist, 1991; Larson et al., 1997; Edwards and Glysson, 1988). Specifically loosely arranged surface samples have to be considered significantly disturbed after retrieval, transport and storage. Instead of trying to preserve the original state, we decided to account for this by installing the sample in the shear boxes in a very loose, not consolidated and fully water saturated state, aiming for conditions representative of submerged beach-face surface sediments which are frequently re-arranged by bed-load transport processes. As we observed the re-arrangement of the loose, unaligned particles during shearing, we argue that the laboratory-prepared samples mimicked fairly well the in situ conditions of recently and loosely deposited sediments which are exposed to increasing shear stress in the swash and surf zone.

A second issue is the applied normal stress. Despite the fact that the lowest normal stress possible, dependent on the specific shear apparatus, was applied in the shear tests, there is no doubt that all tested normal stresses exceeded the normal stresses beach surface sediments are exposed to, a function of the particle weight of the mobile sediment layer. In the case of the large direct shear box and the ring shear, the use of lower normal stresses than standard would have impacted on the operation of the shear boxes, and so was not possible. In the case of the small direct shear box, it was feasible to test at lower normal stresses. According to the Mohr-Coulomb failure criterion, the angle of internal friction $\phi$ derived from direct shear tests in which a range of different normal stresses $\sigma$ was tested is valid for the minimal normal stress scenario as well (see Sect. 2.1). However, Mohr's criterion allows for a curved shape of the failure envelope, representing a nonlinear relationship $\tau_{\mathrm{f}}=f(\sigma)$ (Mohr, 1900; Labuz and Zang, 2012). Additionally, there are concerns as to whether failure stress and friction angles can be properly determined at low stress levels in a shear box (Bruton et al., 2007). For the case of fine sands, Lehane and Liu (2013) demonstrated that a conventional direct shear can indeed be applied at low stress levels, but that corrections might be required, particularly at normal stresses below $10 \mathrm{kPa}$. Their corrections led to a decrease in $\phi$ by $\sim 4^{\circ}$ for $\sigma=4 \mathrm{kPa}$, by $1-2^{\circ}$ for $\sigma=10 \mathrm{kPa}$, and to no significant changes when $\sigma \geq 30 \mathrm{kPa}$. Based on these findings, no corrections were applied in this study because most of the tests were performed at normal stresses significantly above $10 \mathrm{kPa}$. Furthermore, $R^{2} \geq 0.95$ regarding the 
measurements and the fitted Mohr-Coulomb failure criterion line from which the angles of internal friction were determined, and repetition of measurements for specimen from the same sample material delivered consistent results (up to three repetitions per sample). This indicates that the shear box results are reliable and that the angle of internal friction is unlikely significantly biased by the comparably low normal stress measurements.

The question remains of whether the results are applicable to particle remobilization of the beach surface. Bagnold (1966) addresses the principle of solid friction with regard to bed-load transport. He argues that the limiting angle of repose $\alpha$ of a mass of cohesionless granular solids relates the required shear force $T$ to initiate motion under a respective normal force $P$ in the following manner:

$$
T / P=\tan \alpha,
$$

consistent with the Mohr-Coulomb failure criterion. This supports the applicability of the performed shear tests for the investigation of the shearing processes of the beach sediments, and suggests that the observed shearing behavior in the laboratory can be qualitatively transferred to the beach environment. However, some major differences arise resulting from sampling, sample positioning and sample preparation. The issue of sample retrieval has been discussed in a previous paragraph. Other factors are, e.g., beach slope (Rowe, 1962) and the characteristics of hydrodynamic forces exerting shear stress onto the bed. These aspects exceed the scope of this article, but the latter is addressed in Hay et al. (2014). The impact of sample density and packing on the angle of internal friction and the relation to the angle repose however will be discussed in more detail here.

It has been well known since the mid-20th century that the angle of internal friction highly depends on sample density and packing and that it decreases with looser packing (Taylor, 1948; Poulos, 1971). While Bagnold (1966) in his review on the principle of solid friction neglects the possible difference in particle arrangement of a mass of cohesionless granular solids and, thus, assumes that the angle of internal friction approximates the angle of repose, Metcalf (1966) investigates the angle of internal friction in comparison to the angle of repose in more detail. Contrary to the common assumption that the angle of repose equals the angle of internal friction for the loosest particle arrangement, Metcalf (1966) showed that the angle of repose is the angle of internal friction after a first consolidation following the initiation of shearing. For example, for a washed quartz sand he found $\alpha=37^{\circ}, \phi_{\text {loose }}=32^{\circ}$ and $\phi_{\text {consolidated }}=37^{\circ}$. He also observed that the angle of solid friction equaled $37^{\circ}$, consistent with Bagnold (1966). Based on these findings and the negligible deviations between our shear stress measurements for low and larger normal stresses from the Mohr-Coulomb failure criterion approximation, the application of the direct shear test derived angles of internal friction on the bed shear stress scenario at the beach face seems to be justified. Thus, the derived angle of internal friction can be applied as an estimate of angle of repose based on previous literature.

In this study we determined angles of internal friction of $\phi \approx 41-49^{\circ}$ for the flat, elliptic sand from Advocate Beach (Fig. 4) using direct shear (Fig. 7). Considering that the tests were conducted on loose sand samples, these angles of internal friction were significantly larger than what was expected from the literature (i.e., loose sand (rounded): $\phi \approx 27-30^{\circ}$; loose sand (angular): $\phi \approx 30-35^{\circ}$; Das, 1990). Instead, these loose samples fall in the high range of dense sand: $\phi \approx 40$ $45^{\circ}$ (Craig, 1974; Das, 1990). Similarly high friction angles were reported for, e.g., angular rock, metal cubes and elliptic particles by Carson (1977), Carrigy (1970), Cho et al. (2006) and Frette et al. (1996), respectively, highlighting the importance of particle shape. Particularly, the elliptic rice particles had characteristic angles of repose ranging from 46.6 to 51.1 ${ }^{\circ}$ (Frette et al., 1996).

The threshold stress $\tau_{\mathrm{t}}$ of the Advocate sand was estimated using the direct shear box results and the equation suggested by Chepil (1959) and adapted for elliptic particles by Komar and $\mathrm{Li}$ (1986):

$\tau_{\mathrm{t}}=k^{\prime}\left(\rho_{\mathrm{s}}-\rho\right) g I \frac{\tan \phi}{1+0.75 \tan \phi}$,

with $k^{\prime}=1$ an empirical coefficient, the grain density $\rho_{\mathrm{s}}$, water density $\rho$, gravitational acceleration $g$, the length of the intermediate grain axis $I$ and the angle of internal friction $\phi$. The estimated range of $\tau_{\mathrm{t}}$ for the sandy fractions has been indicated by the dark gray patch in Fig. 9 based on a diagram presented by Komar and Li (1986) plotting the grain diameter versus the threshold stress for a variety of particle shapes. Our estimates agree well the curves suggested by Komar and Li (1986) particularly for imbricated, angular to ellipsoid particles. In addition to the above-mentioned high angles of repose for elliptic rice particles, this favorable agreement between our results and the study by Komar and $\mathrm{Li}$ (1986) strengthens the argument that the direct shear tests are applicable to the beach environment and are likely to be useful for the investigation of subaqueous sediment transport.

The friction angles measured for gravel matched the range that has been previously observed for loose gravel (Craig, 1974; Das, 1990; Simoni and Houlsby, 2006). However, mixing the Advocate sand with the gravel led to an immediate increase in the friction angle, expressing the opposite behavior to that observed in other studies in which rounded to sub-angular sand was mixed with gravel. Both Simoni and Houlsby (2006) and Yagiz (2001) described a steady decrease in friction angles with the addition of sand to the gravel sample, while the Advocate sand led to an immediate increase of friction angle after adding $25 \%$ of sand, but remained constant when adding $50 \%$ of sand. This supported the first observation that the Advocate sand withstood exceptionally high shear stresses in comparison to similar particle sizes of rounded or angular shape before failure. Furthermore, this observation may motivate a more detailed 


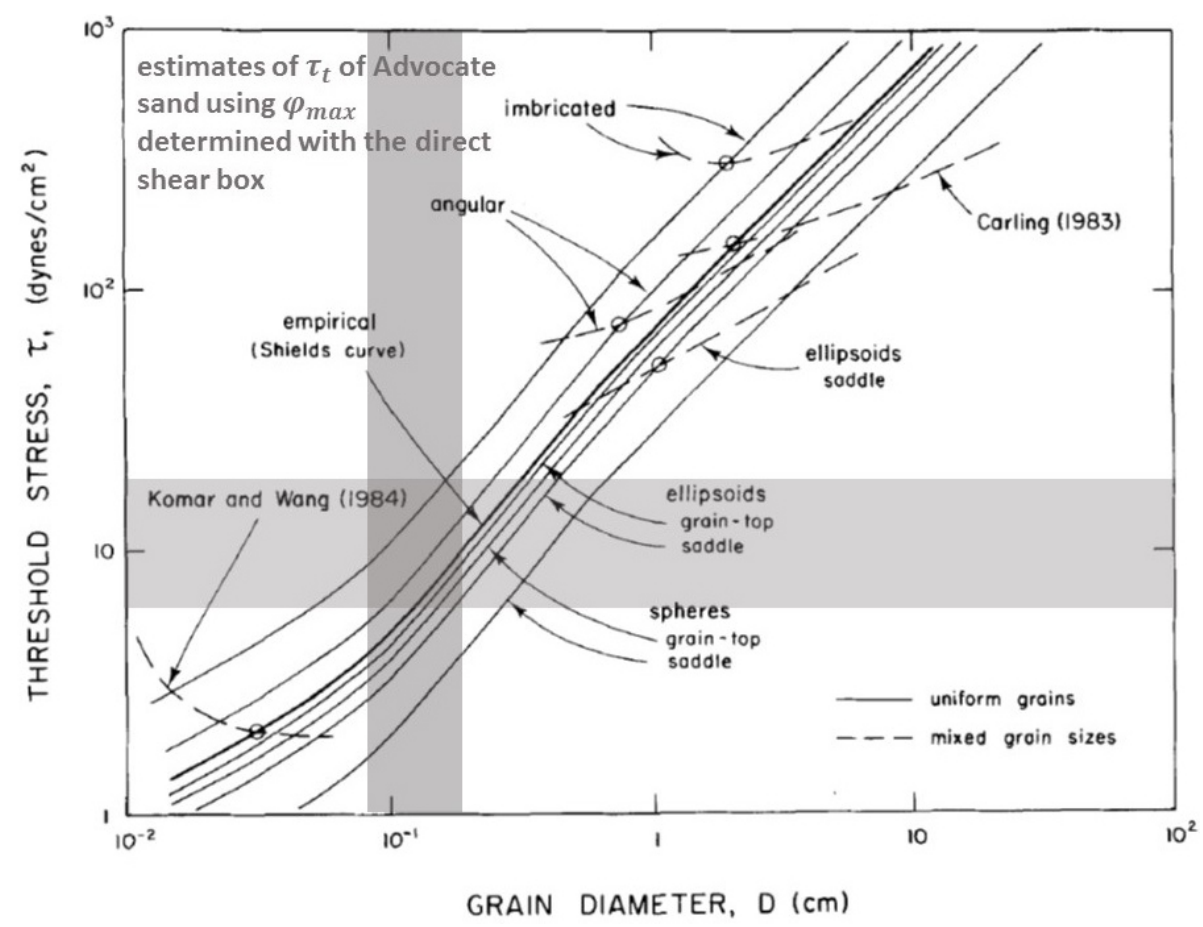

Figure 9. Estimated range of threshold stress based on the shape measurements and direct shear tests of the Advocate sands plotted as the dark gray shade into a scheme by Komar and Li (1986). Our results agree well with their measurements of imbricated, angular and ellipsoid particles in the same size range.

investigation of this issue. Our results suggest that the mixing of elliptic plate-shaped sand with gravel can lead to an increase in the internal friction angle compared to the characteristic internal friction angle of the gravel and that this behavior is related to the particle shape and characteristics of the sand. More detailed geotechnical laboratory investigations are required to test this hypothesis. For beach and other aquatic environments, this finding might imply that specific sands may strengthen a sand-gravel mixture against shear forcing, while often the finer sediments are considered the weak spot in cohesionless mixtures. Investigators have studied the impact of bimodality of sand-gravel mixtures on sediment entrainment and remobilization (Wilcock, 1993; Wilcock and McArdell, 1993; Shvidchenko et al., 2001), but the behavior of the overall mixture and the impact of specific sand characteristics has rarely been the focus of such studies. This research could potentially have a large impact on beach nourishment strategies.

The observed dilatory behavior is another main result of this study. It contributes to the understanding of particle response to shearing in the soil matrix, and offers a conceptual scheme explaining high angles of internal friction and strong resistance to shear of the sand fraction at Advocate Beach (Fig. 10). Again the difference in normal stresses and location of the shear plane must be discussed here. At the beach face, shear is applied to the uppermost sediment surface and failure occurs between the uppermost particle layers. In the phase 1:

re-arrangement of loose surface

particles during shearing

=> compaction

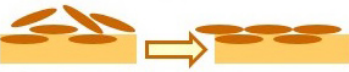

phase 2:

new orientation of particles with extended shearing

$\Rightarrow$ dilation

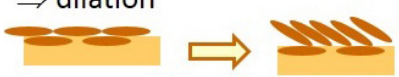

phase 3:

destruction of particles

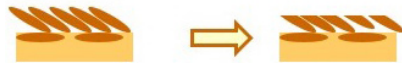

Figure 10. Conceptual sketch of particle arrangement explaining the observed time dependence of vertical displacement during shear.

shear box the failure plane is approximately in the vertical center of the box. Thus, compaction of the specimen is supported, while dilation is hampered by normal stress in the shear box. Nevertheless, we observed a strong dilatory behavior of the Advocate sand specimen after an initial settlement associated with particle rearrangement during initiation of shear force. The samples dilated and remained at a certain 
level of dilation until the end of the test. Even during longterm shearing in the ring shear, the specimen remained in a state of maximum dilation until particles were ground into silt-sized material (Fig. 8). This led to the hypothesis that the Advocate sand re-arranges in a dilatory manner under shearing and that this rearrangement supports a large shear resistance (Fig. 10). Under the negligible normal stresses in the beach scenario, dilation is even easier, allowing a rapid and easy rearrangement of the particle matrix. However, the impact of particle protrusion and lift must be considered here. If one of the elongated particles moves into a more protruded position during the process of particle arrangement, shear and lift forces will increase significantly and will possibly lead to the mobilization of the particle (Bagnold, 1988). Resulting gaps in the sediment matrix and the resulting increase in bed roughness could then lead to a chain reaction of particle mobilizations. These processes are entirely ignored in the shear box tests.

The vertical displacement plots, determined using the small direct shear box and the ring shear apparatus, indicated that the samples underwent different phases of arrangement during shearing. In the following, we propose a concept of particle re-arrangement during the shearing process that may explain the observed vertical displacement and failure shear stresses (Fig. 10). Under first shearing, the loose and unaligned particles rearrange and align corresponding to their shape. This would lead to a denser state of particle packing, explaining a first increase in shear stress and negative vertical displacement. With increasing shear stress, the particles may be erected, again guided by their elongated shape, allowing for higher shear stresses and a strong dilatory behavior (Fig. 10). This arrangement was so strong and final (possibly in an arrangement similar to shingles on a roof) that particles were rather destroyed by grinding than re-arranged again (Fig. 10) during long-term shearing.

A simple physical simulation in which the sand was exposed to the tilting of a smooth tray was used as another independent test of sediment mobilization. The experiment was part of a larger investigation of particle velocity and particle motion in bed-load transport of different particles sizes (Stark et al., 2014a). The tray tilt angle at which mobilization of the sand particles occurred did not match the determined angles of internal friction, which can be explained by the smooth surface of the tray. Thus, the results may only serve for a qualitative comparison. Nevertheless, a clearly delayed mobilization at much higher angles than the tested gravel was observed, confirming that the Advocate sand was resistant to the initiation of particle transport. For future experiments, the impact of the tray surface for testing the angle of repose in comparison to the angle of internal friction can be significantly improved by preparing the tray with a fixed layer particles representing the tray surface as has been demonstrated by several investigators (Miller and Byrne, 1966; Buffington et al., 1992).
In summary, the geotechnical laboratory experiments suggested that the sand fraction at the mixed sand-gravel beach in Advocate, Nova Scotia, has a high resistance towards shear forces and even increases the overall shear resistance when mixed with native gravel. This finding can be explained with the flat and elongated shapes of the sand-sized particles. For the beach environment, it can be concluded that higher shear forces - meaning stronger flows and wave action - are required to mobilize particles than would be assumed from the particle size. When particles are moved, sliding along the flat faces of the particles would be the favored transport behavior, and likely occurs before particle arrangement under increased shearing. When particle arrangement finally takes place, the particle matrix is strengthened by the new arrangement, and more transport and particularly entrainment is hampered. This is in good agreement with the observations at the beach (Hay et al., 2014). No significant change was observed at the beach surface under calm and moderate hydrodynamic conditions. Under storm wave action, sands were shifted and formed ripples with the passing surf zone of the flood tide. During the ebb tide, the ripples were washed out by the retreating surf and swash, leading to a thin fine sand cover of the beach face (Hay et al., 2014). Bed-load transport dominated, while major entrainment of particles appeared unlikely. Only the surf and swash flow conditions were sufficient to trigger significant sediment transport, as no major migration of the ripples was observed. Detailed findings and discussion with respect to flow conditions can be found in Hay et al. (2014).

\section{Conclusions}

Three different types of laboratory tests were performed to assess the behavior of sediments from Advocate Beach during shear: geotechnical direct shear tests and ring shear tests, as well as simple physical simulations of sediment transport initiation. The sediments ranged in size from sandy particles to gravel, and the sand-sized fractures were characterized by a high abundance of flat, elliptic grains. The study was part of a larger effort targeting beach dynamics at Advocate Beach, Bay of Fundy, Nova Scotia.

With regard to the research objectives of this study, the following conclusions can be drawn. (i) It was found that the geotechnical laboratory methods offer important insight into the soil mechanical processes under shear stress and sediment resistance to shear, with potentially important implications for the sediment dynamical behavior at the beach face. (ii) Particularly, it was proposed that the flat, elliptic shape of the Advocate sand undergoes a specific process of particle re-arrangement and alignment that results in a significant increase in angles of internal friction. This strengthens the sand against shearing processes, potentially contributing to the stability of the sand at the beach face against wave action. 
Further investigation is nevertheless needed to better determine how standard geotechnical laboratory experiments should be utilized for the investigation of subaqueous and beach sediment dynamics. The results of this study encourage further pursuit of the issue. This study has demonstrated the importance of particle shape - in particular plate-like shapes - in water-saturated sand-sized sediments subjected to shear stress in the laboratory using a standard geotechnical shear apparatus. In particular, the measured friction angles are very high compared to the values for more rounded particles, a result which we suggest may potentially contribute to the long-term stability of the $1: 10$ slope of the beach face at Advocate.

Acknowledgements. We would like to thank the Natural Sciences and Engineering Research Council of Canada, the Atlantic Innovation Fund, and Nortek for funding; the Advocate field team (L. Zedel, D. Barclay, M. Hatcher, T. Guest and J. Hare) for support in the field; and T. Morton and R. Jamshidi for support during the direct shear experiments. We would also like to thank M. Kleinhans, G. Coco and an anonymous reviewer for suggestions and comments which contributed significantly to the improvement of the article.

Edited by: G. Coco

\section{References}

Amos, C. L. and Long, B.: The sedimentary character of the Minas Basin, Bay of Fundy, in: Proc. Coastlines Canada Conf., Halifax, NS, 1980.

Amos, C. L., Tee, K. T., and Zaitlin, B. A.: The post-glacial evolution of Chignecto Bay, Bay of Fundy, and its modern environment of deposition, Clastic Tidal Sedimentology-memoirs 16, Canadian Society of Petroleum Geologists, Special Publications, 59-89, 1991.

Bagnold, R.: An approach to the sediment transport problem from general physics, US Geol. Surv. Prof. Paper 422, in: The Physics of Sediment Transport by Wind and Water: A collection of hallmark papers, ASCE Publications, Reston, USA, 231-291, 1966.

Bagnold, R.: Beach and nearshore processes part I. Mechanics of marine sedimentation, in: The Physics of Sediment Transport by Wind and Water: A Collection of Hallmark Papers, ASCE Publications, Reston, USA, 188-231, 1988.

Blomqvist, S.: Quantitative sampling of soft-bottom sediments: Problems and solutions, Mar. Ecol.-Prog. Ser., 72, 295-304, 1991.

Bradley, M. P. and Stolt, M. H.: Landscape-level seagrass-sediment relations in a coastal lagoon, Aquat. Bot., 84, 121-128, 2006.

Bruton, D., Carr, M., and White, D.: The influence of pipe-soil interraction on lateral buckling and walking of pipelines-the safebuck JIP, Offshore Site Investigation and Geotechnics, Confronting New Challenges and Sharing Knowledge, 6th International Conference on Offshore Site Investigation and Geotechnics, Confronting new challenges and sharing knowledge, London, UK, 2007.
Buffington, J. M., Dietrich, W. E., and Kirchner, J. W.: Friction angle measurements on a naturally formed gravel streambed: Implications for critical boundary shear stress, Water Resour. Res., 28, 411-425, 1992.

Carrigy, M. A.: Experiments on the Angles of Repose of Granular Materials, Sedimentology, 14, 147-158, 1970.

Carson, M.: Angles of repose, angles of shearing resistance and angles of talus slopes, Earth Surf. Proc., 2, 363-380, 1977.

Chepil, W.: Equilibrium of soil grains at the threshold of movement by wind, Soil Sci. Soc. Am. J., 23, 422-428, 1959.

Cho, G.-C., Dodds, J., and Santamarina, J. C.: Particle shape effects on packing density, stiffness, and strength: natural and crushed sands, J. Geotech. Geoenviron. Eng., 132, 591-602, 2006.

Craig, R. F.: Soil Mechanics, E and FN Spon Press, London, UK, 1974.

Dalrymple, R. W., Knight, R., Zaitlin, B. A., and Middleton, G. V.: Dynamics and facies model of a macrotidal sand-bar complex, Cobequid Bay-Salmon River Estuary (Bay of Fundy), Sedimentology, 37, 577-612, 1990.

Das, B. M.: Principles of geotechnical engineering, PWS, Boston, USA, 1990.

Eagleson, P. and Dean, R.: Wave-induced motion of bottom sediment particles, T. Am. Soc. Civ. Eng., 126, 1162-1185, 1961.

Edwards, T. K. and Glysson, G. D.: Field methods for measurement of fluvial sediment, Department of the Interior, US Geological Survey, pubs.usgs.gov, 1988.

Frette, V., Christensen, K., Malthe-Sørenssen, A., Feder, J., Jøssang, T., and Meakin, P.: Avalanche dynamics in a pile of rice, Nature, 379, 49-52, 1996

Hay, A. E., Zedel, L., Craig, R., and Paul, W.: Multi-frequency, pulse-to-pulse coherent Doppler sonar profiler, in: Current Measurement Technology, 2008, CMTC 2008, IEEE/OES 9th Working Conference, Charlston, USA, 25-29, 2008.

Hay, A. E., Zedel, L., Cheel, R., and Dillon, J.: Observations of the vertical structure of turbulent oscillatory boundary layers above fixed roughness beds using a prototype wideband coherent Doppler profiler: 1. The oscillatory component of the flow, J. Geophys. Res., 117, C03005, doi:10.1029/2011JC007113, 2012a.

Hay, A. E., Zedel, L., Cheel, R., and Dillon, J.: Observations of the vertical structure of turbulent oscillatory boundary layers above fixed roughness using a prototype wideband coherent Doppler profiler: 2. Turbulence and stress, J. Geophys. Res., 117, C03006, doi:10.1029/2011JC007114, 2012b.

Hay, A. E., Zedel, L., and Stark, N.: Sediment dynamics on a steep, megatidal, mixed sand-gravel-cobble beach, Earth Surf. Dynam. Discuss., 2, 117-152, doi:10.5194/esurfd-2-117-2014, 2014.

Illenberger, W. K.: Pebble shape (and size!), J. Sediment. Res., 61, 756-767, 1991.

Kirchner, J. W., Dietrich, W. E., Iseya, F., and Ikeda, H.: The variability of critical shear stress, friction angle, and grain protrusion in water-worked sediments, Sedimentology, 37, 647-672, 1990.

Komar, P. D. and Li, Z.: Pivoting analyses of the selective entrainment of sediments by shape and size with application to gravel threshold, Sedimentology, 33, 425-436, 1986. 
Kuehl, S. A., Nittrouer, C. A., Allison, M. A., Faria, L. E. C., Dukat, D. A., Jaeger, J. M., Pacioni, T. D., Figueiredo, A. G., and Underkoffler, E. C.: Sediment deposition, accumulation, and seabed dynamics in an energetic fine-grained coastal environment, Cont. Shelf Res., 16, 787-815, 1996.

Labuz, J. F. and Zang, A.: Mohr-Coulomb failure criterion, Rock Mech. Rock Eng., 45, 975-979, 2012.

Larson, R., Morang, A., and Gorman, L.: Monitoring the coastal environment; part II: Sediment sampling and geotechnical methods, J. Coast. Res., 13, 308-330, 1997.

Lehane, B. and Liu, Q.: Measurement of shearing characteristics of granular materials at low stress levels in a shear box, Geotech. Geol. Eng., 31, 329-336, 2013.

Li, Z. and Komar, P. D.: Laboratory measurements of pivoting angles for applications to selective entrainment of gravel in a current, Sedimentology, 33, 413-423, 1986.

Masson, D., Harbitz, C., Wynn, R., Pedersen, G., and Løvholt, F.: Submarine landslides: Processes, triggers and hazard prediction, Philos. T. Roy. Soc. A, 364, 2009-2039, 2006.

Metcalf, J.: Angle of repose and internal friction, in: International Journal of Rock Mechanics and Mining Sciences \& Geomechanics Abstracts, vol. 3, Elsevier, Oxford, UK, 155-161, 1966.

Middleton, G. V. and Southard, J. B.: Mechanics of sediment movement, SEPM, Tulsa, USA, 1984.

Miller, R. L. and Byrne, R. J.: The angle of repose for a single grain on a fixed rough bed, Sedimentology, 6, 303-314, 1966.

Mohr, O.: Welche Umstände bedingen die Elastizitätsgrenze und den Bruch eines Materials, Z. Verein. Deut. Ing., 46, 1524-1530, 1900.

Poulos, S. J.: The Stress-Strain Curves of Soils, Geotechnical Engineers Incorporated, Winchester, USA, 1971.

Riley, G. and Mann, G.: Effects of particle shape on angles of repose and bulk densities of a granular solid, Mater. Res. Bull., 7, 163169, 1972.

Rowe, P. W.: The stress-dilatancy relation for static equilibrium of an assembly of particles in contact, P. Roy. Soc. Lond. A, 269, 500-527, 1962.
Santamarina, J. and Cho, G.: Soil behaviour: The role of particle shape, in: Advances in geotechnical engineering: The skempton conference, vol. 1, Thomas Telford, London, UK, 604-617, 2004.

Schanz, T. and Vermeer, P.: Angles of friction and dilatancy of sand, Geotechnique, 46, 145-152, 1996.

Shvidchenko, A. B., Pender, G., and Hoey, T. B.: Critical shear stress for incipient motion of sand/gravel streambeds, Water Resour. Res., 37, 2273-2283, 2001.

Simoni, A. and Houlsby, G. T.: The direct shear strength and dilatancy of sand-gravel mixtures, Geotech. Geol. Eng., 24, 523549, 2006.

Simons, D. B. and Şentürk, F.: Sediment transport technology: Water and sediment dynamics, Water Resources Publication, Littleton, USA, 1992.

Soulsby, R.: Dynamics of marine sands: A manual for practical applications, Thomas Telford, London, UK, 1997.

Stark, N., Hay, A., Cheel, R., Zedel, L., and Barclay, D.: Laboratory Measurements of Coarse Sediment Bedload Transport Velocity Using a Prototype Wideband Coherent Doppler Profiler (MFDop), J. Atmos. Ocean. Tech., 31, 999-1011, 2014a.

Stark, N., Hay, A., and Zedel, L.: Sedimentological and morphological variations at a macro-tidal sandy gravel beach, Mar. Geol., in preparation, 2014b.

Taylor, D. W.: Fundamentals of soil mechanics, Soil Sci., 66, 83163, 1948.

Terzaghi, K.: Theoretical soil mechanics, Wiley \& Sons, Hoboken, USA, 1943.

Terzaghi, K.: Soil mechanics in engineering practice, John Wiley \& Sons, Hoboken, USA, 1996.

Wilcock, P. R.: Critical shear stress of natural sediments, J. Hydraul. Eng., 119, 491-505, 1993.

Wilcock, P. R. and McArdell, B. W.: Surface-based fractional transport rates: Mobilization thresholds and partial transport of a sand-gravel sediment, Water Resour. Res., 29, 1297-1312, 1993.

Yagiz, S.: Brief note on the influence of shape and percentage of gravel on the shear strength of sand and gravel mixtures, Bull. Eng. Geol. Environ., 60, 321-323, 2001. 